\title{
Proteinuria, pancytopenia and hypoxaemic respiratory failure in a 28-year-old female
}

\author{
W. Berjaoui*, N. Dean**\# and N. Dahle
}

\section{CASE REPORT}

A previously healthy 28 -yr-old Caucasian female presented to the emergency department with a 1-week history of generalised body swelling that was followed by pleuritic chest pain radiating to the patient's back. She had mild shortness of breath, cough and palpitations, but no fever, chills, nausea, vomiting or diarrhoea. No medications were taken except oral contraceptives. She denied any history of tobacco or alcohol use, recent travel or sick contacts.

The patient's vital signs were as follows: 1) blood pressure $135 / 94 \mathrm{mmHg} ; 2$ ) body temperature $39.4^{\circ} \mathrm{C} ; 3$ ) respiratory rate 16 breaths $\cdot \mathrm{min}^{-1}$; 4) pulse 105 beats $\cdot \mathrm{min}^{-1}$; and 5) oxygen saturation $95 \%$, while breathing room air. Her physical examination was remarkable for decreased breath sounds diffuse with minimal crackles, as well as facial swelling and pitting oedema of the lower extremities.

Pertinent laboratory results of the blood tests performed on admission are shown in table 1.

After significant respiratory distress, requiring noninvasive positive pressure ventilation, the patient was admitted to the intensive care unit and was started empirically on i.v. ceftriaxone, azithromycin and furosamide. Over the next few days, she remained febrile with worsening hypoxaemia. Her white blood cell count dropped to $2.2 \times 10^{9}$ cells $\cdot \mathrm{L}^{-1}$ with a haemoglobin level of $90 \mathrm{~g} \cdot \mathrm{L}^{-1}$ and platelet count of $82 \times 10^{9}$ cells. $\mathrm{L}^{-1}$. Chest radiography (fig. 1 ) and contrast-enhanced computed tomography (CT) scan of the thorax (fig. 2) were performed. Clear pleural fluid $(500 \mathrm{~mL})$ was aspirated by thoracentesis. Pleural fluid analysis was consistent with a transudative effusion (protein $<20 \mathrm{~g} \cdot \mathrm{L}^{-1}$; lactate dehydrogenase $313 \mathrm{IU}$ with a serum level of $658 \mathrm{IU})$.

Bronchoscopy revealed mild mucosal erythema with mild increase in secretions. No endobronchial lesions were seen. Bronchoalveolar lavage (BAL) showed an increased number of lymphocytes. Cultures and special stains were negative.

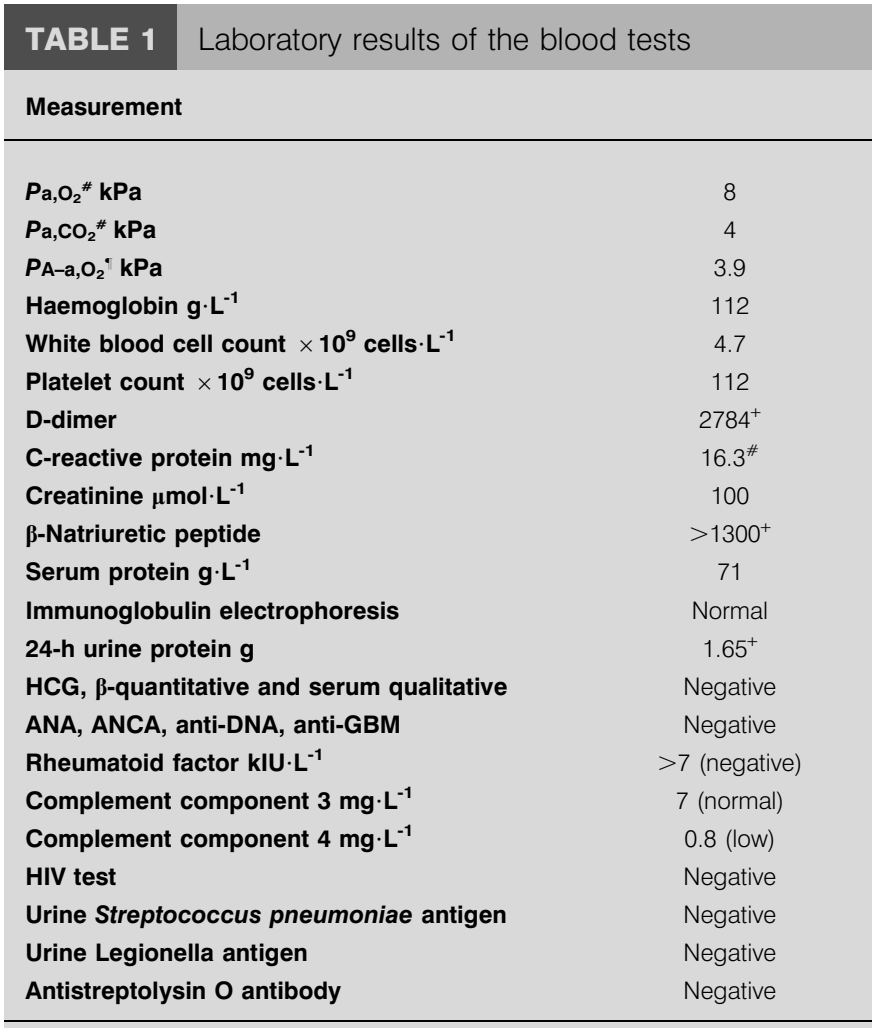

$\mathrm{Pa}_{1} \mathrm{O}_{2}$ : arterial oxygen tension; $\mathrm{Pa}_{\mathrm{a}} \mathrm{CO}_{2}$ : arterial carbon dioxide tension; $\mathrm{PA}-\mathrm{a}, \mathrm{O}_{2}$ : alveolar-arterial oxygen tension difference; HCG: human chorionic gonadotrophin; ANA: antinuclear antibody; ANCA: antineutrophilic cytoplasmic antibody; GBM: glomerular basement membrane. ${ }^{\#}$ : in room air; ": at $1,400-\mathrm{m}$ altitude; + : elevated. $1 \mathrm{mmHg}=0.33 \mathrm{kPa}$.

An echocardiogram was normal. Right heart catheterisation showed a cardiac output of $10 \mathrm{~L} \cdot \mathrm{min}^{-1}$, pulmonary pressure of $28 / 7 \mathrm{mmHg}$ (mean $19 \mathrm{mmHg}$ ), pulmonary wedge pressure of $10 \mathrm{mmHg}$ and a central venous pressure of $4 \mathrm{mmHg}$.

\footnotetext{
*Division of Pulmonary and Critical Care Medicine, Dept of Medicine, "School of Medicine, University of Utah, and ${ }^{\#}$ Division of Pulmonary and Critical Care Medicine, Dept of Medicine, LDS Hospital, Salt Lake City, UT, USA. 

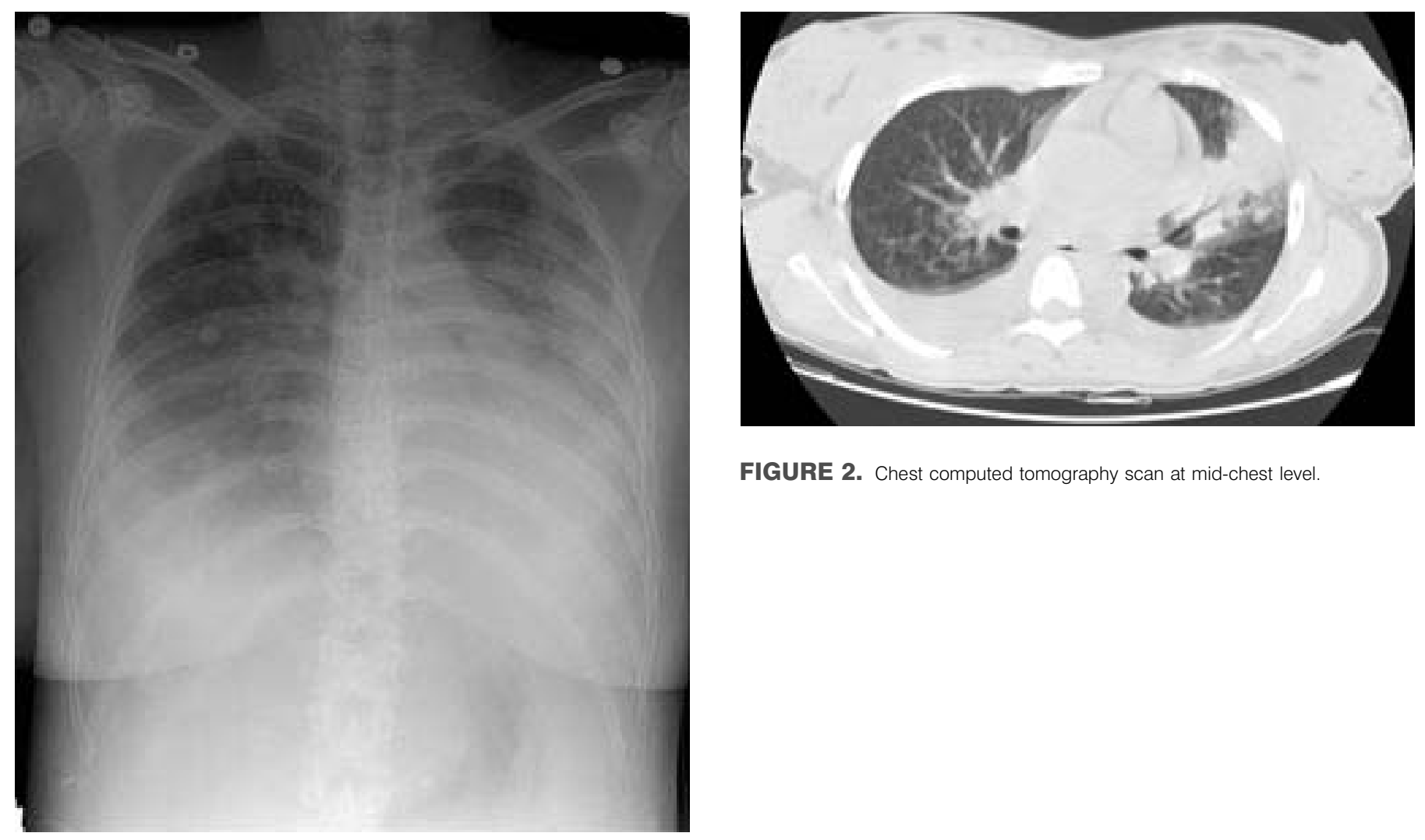

FIGURE 2. Chest computed tomography scan at mid-chest level.

FIGURE 1. Supine antero-posterior chest radiograph.

BEFORE TURNING THE PAGE, INTERPRET THE RADIOGRAPH AND COMPUTED TOMOGRAPHY SCAN, AND SUGGEST A DIAGNOSIS AND TREATMENT. 


\section{INTERPRETATION}

\section{Chest radiography}

Portable supine antero-posterior chest radiography demonstrated diffuse parenchymal opacities with obliteration of the costophrenic sinus, suggesting the presence of bilateral pleural effusions. An air bronchogram is seen in the left lower lobe. Cardiomegaly is suggested by the ratio of the heart diameter to that of the chest, although this is a supine film (fig. 1).

\section{Computed tomography}

Contrast-enhanced CT scan of the thorax revealed moderate bilateral pleural effusions, and bilateral areas of airspace consolidation involving the lingula and lower lobe consistent with pneumonia. There was no evidence of central pulmonary emboli (fig. 2).

\section{Diagnostic considerations}

The current authors considered the following diagnoses: 1) vasculitis or collagen vascular diseases involving the lung and pleural tissues and causing a renal-pulmonary syndrome; 2) hydrostatic pulmonary oedema given the presence of bilateral transudative effusions and elevated $\beta$-natriuretic peptide; 3) immunodeficiency states; 4) bronchioalveolar carcinoma; and 5) viral pneumonia given the febrile presentation associated with BAL lymphocytosis and serum pancytopenia.

The negative vasculitis serology made the diagnosis of vasculitis less likely. The possibility of hydrostatic pulmonary oedema led the current authors to perform right heart catheterisation despite normal echocardiographic findings, but was excluded by the measured cardiac output of $10 \mathrm{~L} \cdot \mathrm{min}^{-1}$ and normal capillary wedge pressure. Transudative pleural effusions have previously been reported in viral pneumonia, as appears to be the case in the presented patient [1]. Another possible explanation for the transudate is the significant proteinuria that caused the generalised oedema in the patient. The lack of history of recurrent infections and the negative HIV test made immunodeficiency status unlikely. The rapid changes in the chest radiograph, as well as the absence of airway abnormalities seen during bronchoscopy, negative pleural effusion cytology for malignancy and lack of smoking history ruled out bronchoalveolar carcinoma.

The following tests to investigate an infectious aetiology were carried out (table 2).

\section{Diagnosis: Disseminated parvovirus B19 infection.}

\section{CLINICAL COURSE AND TREATMENT}

The current patient improved with supportive therapy (oxygen, fluids and noninvasive positive ventilation) and was discharged home 1 week after admission. She was seen 2 weeks later in clinic where she had no symptoms, normal oxygen saturation and a normal chest radiograph.

\section{DISCUSSION}

Parvovirus B19 belongs to the parvoviridae family with a predilection to erythroid cells. Infection with parvovirus B19 occurs worldwide with $>70 \%$ of adults having positive antibodies [2]. Transmission is commonly via respiratory droplets, and less commonly through vertical transmission from an infected mother to the foetus [3]. Parvovirus can also spread via blood products [4]. Children are the main source of

\begin{tabular}{|c|c|}
\hline Test & Result \\
\hline Viral hepatitis profile & Negative \\
\hline CMV PCR & Negative \\
\hline HSV EIA & Negative \\
\hline Mycoplasma pneumoniae antibody, IgM & Negative \\
\hline $\begin{array}{l}\text { Coccidioides antibody by complement } \\
\text { fixation }\end{array}$ & Negative \\
\hline Infectious mononucleosis screen & Negative \\
\hline Rapid influenza A and B virus antigen & Negative \\
\hline \multicolumn{2}{|l|}{ Parvovirus B19 antibodies $\#$} \\
\hline $\lg G I U$ & 4.80 \\
\hline $\lg M I U$ & 5.27 \\
\hline Parvovirus PCR & Positive \\
\hline
\end{tabular}

respiratory transmission with household contacts and day carers being at a higher risk. Transmission to healthcare workers seems to depend on the degree of contact $[5,6]$.

Parvovirus is a common human pathogen. It is known to cause severe illness in children, pregnant females, immunocompromised hosts, as well as patients with haematological diseases. However, severe illness in immunocompetent adults is not common. Most infections are asymptomatic. The most common manifestation is erythema infectiosum or "fifth disease", which is a febrile exanthem. The disease tends to be more severe in adults. A clinically significant arthropathy is seen in $10-33 \%$ of infected individuals, being highest in middle-aged females and lowest in children [7]. Long-term sequelae are rare. Acute parvovirus infection during pregnancy, especially in the first trimester, can lead to miscarriage and hydrops foetalis [8].

Diagnosis is based on serological and DNA evidence. Enzyme immunoassay has a reported sensitivity of $89.1 \%$ and a specificity of $99.4 \%$. Immunoglobulin (Ig)M antibodies usually appear within 7-10 days of exposure and can persist for several months. Therefore, low titres of $\operatorname{IgM}$ can be suggestive but not conclusive of acute infection. This is also true for parvovirus B19-specific DNA which can persist for years, especially in immunocompromised patients $[9,10]$.

Pulmonary involvement with parvovirus is extremely rare, especially in healthy individuals. Two cases were reported in immunocompromised children [11, 12]. The present authors could find only one previous case report of severe respiratory involvement in a previously healthy adult [13]; that patient was a middle-aged diabetic female with history of tobacco and intravenous drug abuse, which raises questions about the patient's immunocompetency. Two mild cases of pulmonary involvement with parvovirus in healthy individuals causing pleuropneumonitis and pulmonary oedema, respectively, have been reported $[14,15]$.

The presented case appears to be the first report of severe pulmonary compromise in a completely healthy individual due to infection with parvovirus B19. 


\section{REFERENCES}

1 Thijsen SFT, Luderer R, van Gorp JMH, Oudenjans SJ, Bossink AW. A possible role for Epstein-Barr virus in the pathogenesis of pleural effusion. Eur Respir J 2005; 26: 662-666.

2 Cohen BJ, Buckley MM. The prevalence of antibody to human parvovirus B19 in England and Wales. J Med Microbiol 1988; 25: 151-153.

3 Jordan JA. Identification of human parvovirus B19 infection in idiopathic nonimmune hydrops fetalis. Am J Obstet Gynecol 1996; 174: 37-42.

4 Jordan J, Tiangco B, Kiss J, Koch W. Human parvovirus B19: prevalence of viral DNA in volunteer blood donors and clinical outcomes of transfusion recipients. Vox Sang 1998; 75: 97-102.

5 Ray SM, Erdman DD, Berschling JD, Cooper JE, Torok TJ, Blumberg HM. Nosocomial exposure to parvovirus B19: low risk of transmission to healthcare workers. Infect Control Hosp Epidemiol 1997; 18: 109-114.

6 Bell LM, Naides SJ, Stoffman P, Hodinka RL, Plotkin SA. Human parvovirus B19 infection among hospital staff members after contact with infected patients. $N$ Engl J Med 1989; 321: 485-491.

7 Moore TL. Parvovirus-associated arthritis. Curr Opin Rheumatol 2000; 12: 289-294.
8 Levy R, Weissman A, Blomberg G, Hagay ZJ. Infection by parvovirus B 19 during pregnancy: a review. Obstet Gynecol Surv 1997; 52: 254-259.

9 Erdman DD. Human parvovirus B19: laboratory diagnosis. In: Anderson LJ, Young NS, eds. Human Parvovirus B19. Vol. 20 of Monographs in Virology. Basel, Karger, 1997; pp. 93-104.

10 Zerbini M, Gallinella G, Cricca M, Bonvicini F, Musiani M. Diagnostic procedures in B19 infection. Pathol Biol (Paris) 2002; 50: 332-338.

11 Janner D, Bork J, Baum M. Severe pneumonia after heart transplantation as a result of human parvovirus B19. J Heart Lung Transplant 1994; 13: 336-338.

12 Bousvaros A, Sundel R, Thorne GM, et al. Parvovirus B19associated interstitial lung disease, hepatitis, and myositis. Pediatr Pulmonol 1998; 26: 365-369.

13 Wardeh A, Marik P. Acute lung injury due to parvovirus pneumonia. J Int Med 1998; 244: 257-260.

14 Nikkari S, Lappalainen H, Saario R, Lammintausta K, Kotilainen P. Detection of parvovirus B19 in skin biopsy, serum, and bone marrow of a patient with fever, rash, and polyarthritis followed by pneumonia, pericardial effusion, and hepatitis. Eur J Clin Microbiol Infect Dis 1996; 15: 954-957.

15 Schmid ML, McWhinney PH, Will E. Parvovirus B19 and glomerulonephritis in a healthy adult. Ann Intern Med 2000; 132: 682. 